\title{
Design of Compact Broadband Omnidirectional Canonical Sleeve Antenna covering UHF band
}

\author{
Chandana SaiRam ${ }^{1}$, DameraVakula ${ }^{2}$ and Mada Chakravarthy ${ }^{3}$ \\ ${ }^{1}$ National Institute of Technology, Warangal, Telangana, India, and \\ DLRL, Hyderabad, Pin Code: 5000 05, Telangana, India. \\ ${ }^{2}$ National Institute of Technology, Pin Code: 506004, Telangana, India \\ ${ }^{3}$ DLRL, Hyderabad, Pin Code: 5000 05, Telangana, India. \\ *corresponding author, E-mail: sairamchandana@yahoo.co.in
}

\begin{abstract}
A novel compact broadband Canonical Sleeve Antenna (CSA) covering 500-3600 $\mathrm{MHz}$ with omnidirectional characteristics is presented in this paper. A new method is employed in which the radiating antenna structure is designed as combination of three different canonical structures: hemispherical, conical and cylindrical elements. To accomplish broad bandwidth with compact size, dipole antenna is designed by using cylindrical sleeve over the hemispherical dipole with conical extensions and cylindrical attachments. Performance characteristics of CSA is simulated and compared with BiConical Antenna (BCA) and other antenna configurations and found to be best antenna configuration with compact form factor. The antenna has height of $111.43 \mathrm{~mm}$ and diameter of $116.66 \mathrm{~mm}$. Simulation studies are carried out using CST Microwave Studio. The simulated results are validated by fabricating CSA and evaluating its performance metrics. CSA has 7.2:1 bandwidth with measured VSWR $<2.7: 1$ and gain varies from 0 to $3.6 \mathrm{dBi}$. The antenna finds use in wireless communication, spectrum monitoring and defense applications.
\end{abstract}

\section{Introduction}

The rapid spurt in communication and wireless industry has created a great demand for compact omnidirectional antennas for trans-receive applications. Half wave dipole and a quarter wave monopole antennas are the simplest omnidirectional antennas. The use of these antennas is restricted to narrow band applications due to their resonant behavior [1]. Biconical antennas and Monocone antennas have broadband omnidirectional characteristics. However, these antennas are bulkier and occupy large size, especially, when implemented in $\mathrm{VHF} / \mathrm{UHF}$ band [2].

The bandwidth of monopole antennas can be increased by implementing sleeve concept. A wide-band sleeve cage monopole and sleeve helical antennas are reported covering 350-1550 MHz and 500-1750 MHz for a VSWR $\leq 3.5: 1$ respectively [3]. But, the sleeve monopole antennas require a very large ground plane of $5.5 \mathrm{~m} \mathrm{x}$ $6.7 \mathrm{~m}$. M.Ali et al. reported a dual meander sleeve antenna covering Personal Communication Network bands in 850$2050 \mathrm{MHz}$ [4]. The antenna uses a square ground plane of $900 \mathrm{~mm} \times 900 \mathrm{~mm}$ and achieves VSWR $<3: 1$. But the radiation patterns and gain of the antenna are not reported in the published work. The requirement of large ground plane for sleeve monopole antenna often creates implementation problems. Bin Zhou et al. presented a sleeve antenna mounted on a metal cylinder covering 105$420 \mathrm{MHz}$ which has a bandwidth ratio of $4: 1$ for VSWR of $3: 1$ [5]. However, the antenna has large size. The gain of the antenna is less than $0 \mathrm{dBi}$ over certain operating frequencies. The bandwidth of the antenna is increased with inductance and capacitance matching networks to operate between $225-600 \mathrm{MHz}$ with gain above $0 \mathrm{dBi}$. James L. McDonal et al. has designed a cylindrical dipole with biconically offset feed to operate between 200-2000 $\mathrm{MHz}$. It is published in the paper, that the conical feed improved impedance and pattern bandwidths. But, the Eplane patterns have nulls in broad side direction above $400 \mathrm{MHz}$ [6].

Chritz Duncan et al. reported a planar half disc dipole antenna with size reduced by half when compared to circular dipole antenna. The antenna has broadband characteristics from 2.016-6.38 GHz which gives a bandwidth ratio of 3.16:1 [7]. In general, application of shorting pins enhances the impedance bandwidth of monopole antennas. Fractal-shaped antenna has also been useful for broadband bandwidth covering from $800 \mathrm{MHz}$ to $6 \mathrm{GHz}[8]$.

A sleeve monopole antenna with cylindrical element having disc loading and shorting posts is reported over a frequency band of $350-1300 \mathrm{MHz}$. The antenna has impedance bandwidth ratio of 3.7:1 for 3:1 VSWR [9]. But the antenna requires a ground plane for its operation and also gain of the antenna is not mentioned.

An illustration is given on a 4:1 impedance bandwidth top loaded monopole antenna with open sleeve configuration, loaded with a series resistor and inductance 
elements. The antenna requires ground plane for its operation and the antenna gain varies from -7 to $1.5 \mathrm{dBi}$ [10]. In practice, sleeve antenna configurations along with top loading and lumped matching networks are utilized to get small size broadband antennas. The main drawback of loaded antenna is reduction in efficiency due to losses in the circuit. Resistively loading of antenna for bandwidth improvement is established for monopole antenna [11]. The antenna is designed for $0.17-0.52 \mathrm{GHz}$ frequency range and an efficiency of $23.85 \%$ is obtained at $0.2 \mathrm{GHz}$. Hence, it can be shown that broad bandwidth is achieved at the expense of efficiency. This is a compromise to achieve broad bandwidth with resistive loading.

Waqas Mazhar et al. proposed a broadband sleeve monopole antenna with capacitive loads, matching network and impedance transformer [12]. The antenna operates a wide frequency range of 84-890 $\mathrm{MHz}$. However, the E-plane patterns exhibit nulls along broadside direction of the order of $5 \mathrm{~dB}$ which are not desirable and also gain of the antenna is not stated. K.George Thomas et al. demonstrated a dual sleeve top loaded monopole antenna for $0.5-2.1 \mathrm{GHz}$ [13]. The return loss and radiation patterns of the antenna are presented, but gain of the antenna is not mentioned. A comparison of simulated and measured results is done for broadband rectangular sleeve dipole in $850-2500 \mathrm{MHz}$ [14]. Tao Jian et al. designed a multiple sleeve dipole in 0.8-2.5 GHz for bandwidth ratio of 3.125: 1 [15].

Antenna structures other than cylindrical shapes are suggested for broad bandwidth and size reduction. In addition, various sleeve configurations can also be included in antenna design for better performance. S.L.Zuo et al. developed a conical radiator with cylindrical sleeve [16]. The antenna covers 750-2660 $\mathrm{MHz}$, giving a bandwidth ratio of $3.54: 1$ with a circular ground plane of radius $150 \mathrm{~mm}$. Z.-Y. Zhang et al. presented a conical sleeve monopole with shorting pins [17]. This low profile antenna covers 446-732 $\mathrm{MHz}$ giving a bandwidth ratio of 1.64:1. The antenna requires a ground plane of radius $200 \mathrm{~mm}$.

In the present paper, the concept of shaped radiators using canonical shapes and cylindrical sleeve are used to design a compact omnidirectional antenna. The proposed antenna uses distributed loading impedance matching techniques and achieves an instantaneous bandwidth of 7.2:1 covering 500-3600 MHz.

\section{Canonical Sleeve antenna (CSA)}

\subsection{Design approach and implementation}

In the present paper, the concept of shaped radiators is applied for dipole using canonical shapes to design a compact omnidirectional antenna in UHF band. To accomplish broad bandwidth with compact size, CSA design is improved by employing cylindrical sleeves. In the antenna design distributed loading impedance matching techniques are adopted.
It is aimed to design a compact omnidirectional antenna covering 500-3600 MHz. To cover applications in UHF communications, the starting frequency for design is considered as $500 \mathrm{MHz}$. By increasing the bandwidth of the antenna on the upper side, the antenna can be used over a wider spectrum.

A Solid BiConical Antenna (BCA) is first designed for an optimized diameter, height of Cone and feed gap. The structure of antenna is shown in fig. 1(a). BCA also serves the purpose of bench marking the performance of the proposed antenna. Bandwidth of Biconical antenna can be improved by varying the cone angle between $60^{\circ}$ and $120^{\circ}$. The arrived angle of the cone is $112.16^{\circ}$ for the proposed BCA. BCA meets the impedance matching goal. But, the gain of BCA is reduced at $1.5 \mathrm{GHz}$. The summary of results of BCA antenna is shown in Table 1.

The geometry of a Hemisperical Dipole Antenna (HDA) is shown in Fig. 1(b). HDA occupies more volume than BCA of same diameter and has smooth transition in its structure, leading to better design concept.

HDA is designed and the results given in Table 1 . The performance of HDA is better than BCA with gain more than $0 \mathrm{dBi}$ over the frequency band $0.5-3.6 \mathrm{GHz}$. However, the dimension of HDA is more than BCA.

To realize a reduced size antenna, $\mathrm{BCA}$ structure is truncated from its tip to height of $22.18 \mathrm{~mm}$ and replaced with hemispherical dipole, leading to geometry of Hemispherical Dipole with Conical extensions (HDC) as shown in fig. 1(c).

The optimized dimensions of HDC are shown in Table 1. HDA has good impedance characteristics and gain varies from 0.7 to $3.2 \mathrm{dBi}$. To further improve the antenna performance, top loading concept is used by adding cylinders to HDC, leading to hemispherical dipole with conical extensions and Cylindrical top Loading (HDCCL) as shown in fig. 1(d).

Top loading increases capacitance and reduces the antenna height. HDCCL has good impedance characteristics and gain varies from 0.4 to $3.6 \mathrm{dBi}$. To improve the antenna radiation characteristics, a novel sleeve is designed. A conventional sleeve dipole has a cylindrical dipole with cylindrical sleeve over it as shown in fig. 1(e). In the proposed work, a cylindrical sleeve is used over HDCCL resulting in configuration of CSA as shown in fig. 1(f). The design concept used in this paper is to use a combination of canonical structures like hemisphere, cone and cylinder to replace the cylindrical dipole in a conventional sleeve dipole antenna. A sleeve length of $7.3 \mathrm{~mm}$ is designed. The sleeve is supported over the hemispherical elements using dielectric cylindrical supports made up of Poly Urethane Foam (PUF) having dielectric constant of 1.4.

CSA has the compact form among the antennas studied and good impedance and gain characteristics. The simulated gain varies from 0.25 to $4.4 \mathrm{dBi}$.

The optimised dimensions for the antenna configuration of BCA, HDA, HDC, HDCCL and CSA for best impedance match in $500-3600 \mathrm{MHz}$ are given in 
Table 1. It can be inferred that HDA has the largest dimensions. BCA has the lowest height and HDC has the lowest diameter. CSA has optimum dimensions with Height x Diameter : $111.43 \mathrm{~mm} \times 116.66 \mathrm{~mm}$. CSA occupies the lowest volume among all the antennas and hence has a compact form factor. CSA has height $11.77 \%$ more and the diameter $21.32 \%$ less compared to the BCA.

The comparison of simulated VSWR of antenna configurations of fig. 1 (a) to $1(d)$ and $1(f)$ is shown in fig. 2. VSWR of all the antennas is less than $3: 1$. It can be inferred that the VSWR of HDA is improved by adding conical extensions to it (leading to HDC). HDC has the best impedance matching characteristics.

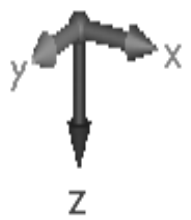

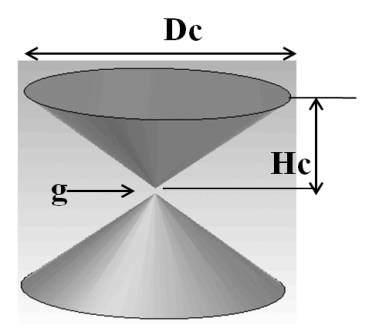

(a)

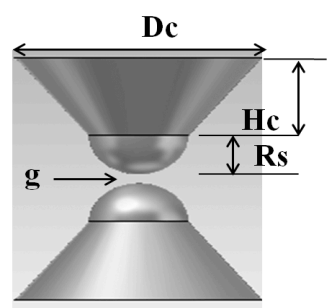

(c)

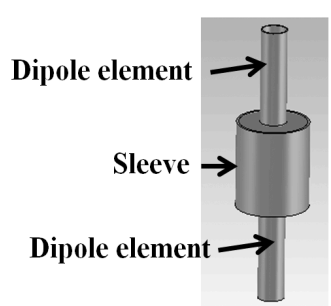

(e)

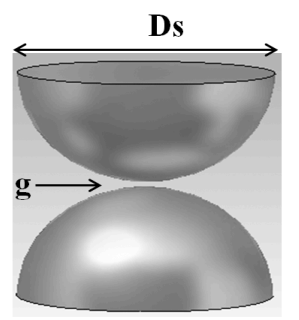

(b)

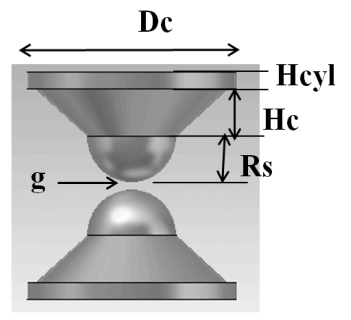

(d)

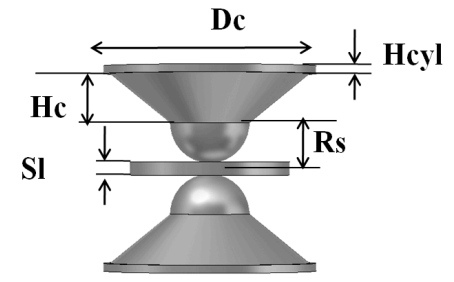

(f)

Figure 1: Various types of antenna configurations studied (a) Biconical Antenna (BCA), (b) Hemispherical Dipole Antenna (HDA) (c) Hemispherical Dipole with Conical Extensions (HDC) (d) Hemispherical Dipole with Conical Extensions and Cylindrical loading (HDCCL) (e) Geometrical configuration of sleeve dipole antenna (f) Canonical Sleeve Antenna (CSA)

VSWR of CSA is than BCA in low frequency region and both antennas have VSWR less than 2.5:1 from 0.525 $\mathrm{GHz}-3.6 \mathrm{GHz}$. The simulation studies of these antenna configurations are also carried out for three dimensional radiation characteristics. It is found that CSA has good radiation characteristics compared to other antenna configurations over the frequency band 0.5-3.6 GHz.

It is observed that the BCA has dough nut shaped pattern from $0.5-1 \mathrm{GHz}$ and the pattern starts splitting above $1 \mathrm{GHz}$ up to $2 \mathrm{GHz}$. This leads to reduction in gain of the $\mathrm{BCA}$ in $1-2 \mathrm{GHz}$ at Horizon. (Please refer figure 1 for reference coordinate system. Horizon means is at $90^{\circ}$ from Z-axis and in X-Y plane).

The dough nut shaped pattern is restored above $2 \mathrm{GHz}$ up to $3.6 \mathrm{GHz}$, and as expected, beamwidth reduces as frequency increases. HDA, HDC and HDCCL also exhibits split in dough nut shaped radiation pattern in 11.75 GHz, 3-3.6 GHz and 1.5-2 GHz respectively. This split phenomenon is minimal for CSA and is observed around $1.5 \mathrm{GHz}$.

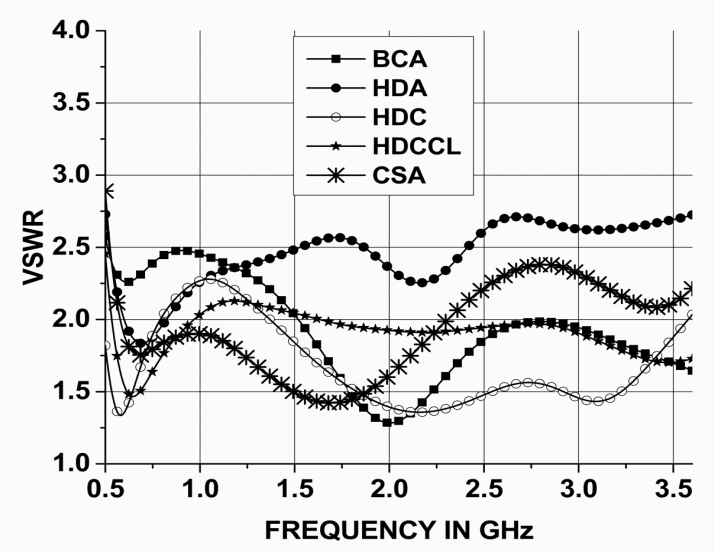

Figure 2: Comparison of Simulated VSWR of antennas

The comparison of Gain at Horizon for all the antenna configurations is shown in figure 3 .

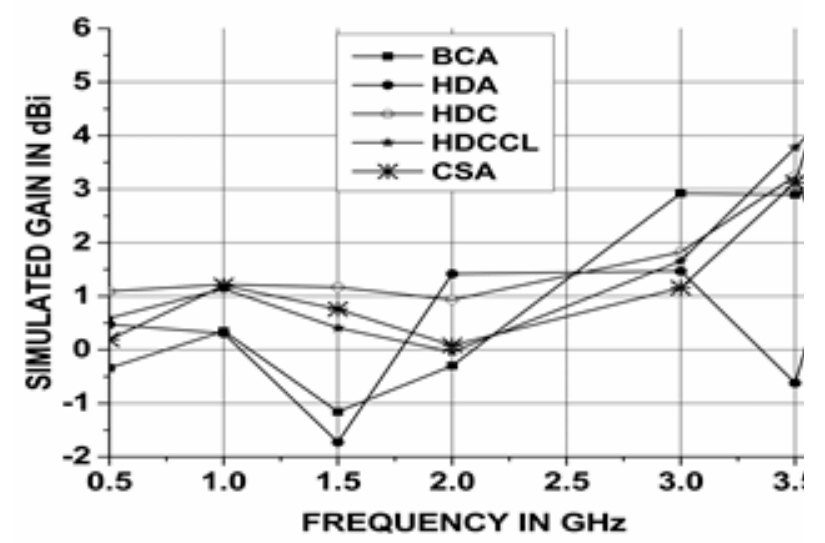

Figure 3: Simulated Gain of antennas at Horizon 
It is observed that CSA exhibits over all good gain characteristics than other antennas despite its small dimensions. The gain of BCA is $-0.3 \mathrm{dBi}$ at $0.5 \mathrm{GHz}$ due to its low height of $99.69 \mathrm{~mm}$ (Gain is proportional to length of the antenna). Reduction in Gain of the order of 2 $\mathrm{dB}$ is found in BCA and HDA configurations around 1.5 $\mathrm{GHz}$, which is undesirable. CSA antenna, though possessing low height exhibits a low intensity dip in Gain around $1.5 \mathrm{GHz}$ and its gain increases with frequency. CSA has the highest gain of $4.2 \mathrm{dBi}$ among the antennas at $3.6 \mathrm{GHz}$. It can be inferred that CSA is the best configuration among the antennas studied in broadband scenario. It has desirable impedance and radiation characteristics even though it has overall compact form factor. The impedance characteristics of CSA are shown in fig. 4.

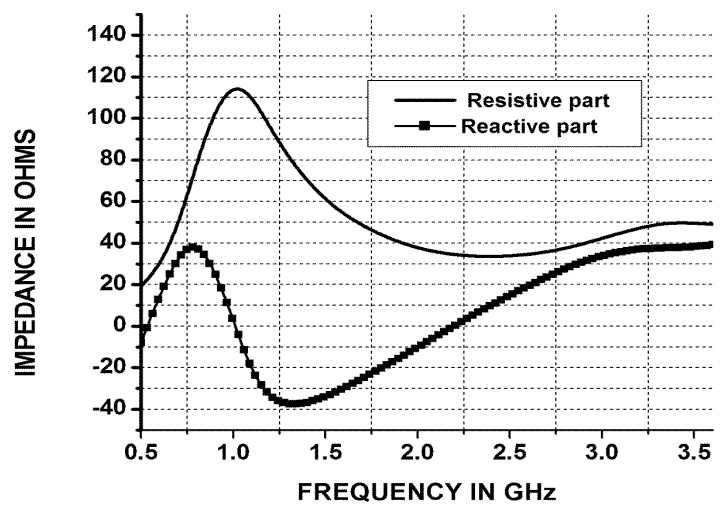

Figure 4: Impedance Characteristics of CSA

All the antenna design values are arrived at by carrying out simulations in CST Microwave Studio. The optimum configurations are arrived by keeping design goal of VSWR $<3: 1$ over the frequency band 0.5-3.6 GHz. The current distribution of $\mathrm{CSA}$ at $0.5 \mathrm{GHz}, 2 \mathrm{GHz}$ and $3.6 \mathrm{GHz}$ is shown in fig. 5. The superior performance of CSA compared to other antenna configurations can be attributed to its optimised geometry and suitable current distribution on it.

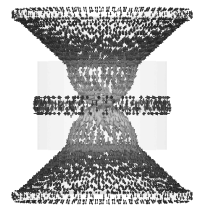

(a)

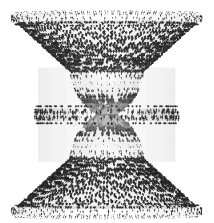

(b)

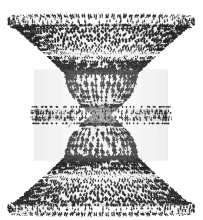

(c)

Figure 5: Simulated surface current distribution of Canonical Sleeve Antenna (CSA) at (a) $0.5 \mathrm{GHz}$ (b) $2 \mathrm{GHz}$ (c) $3.6 \mathrm{GHz}$
The geometrical configuration of CSA is given in fig. 6 showing its isometric, front and sectional views.

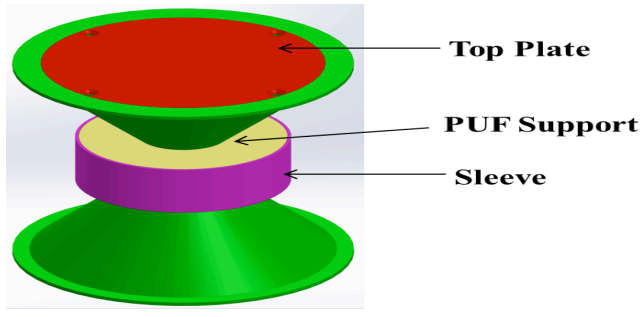

6 (a) Isometric View

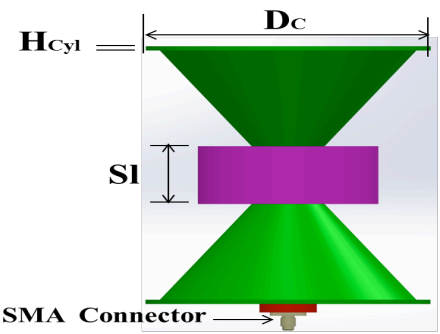

6 (b) Front View

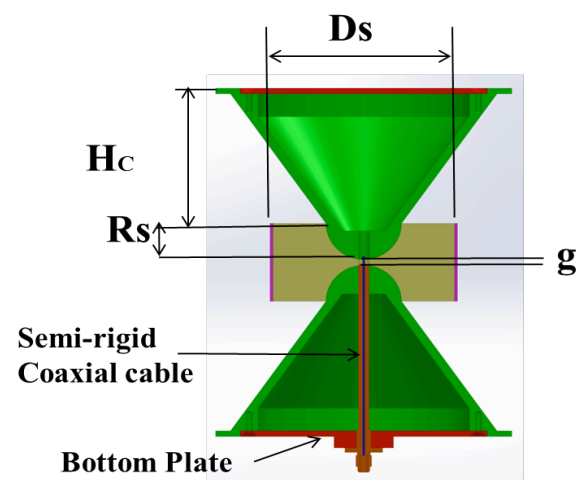

6 (c) Sectional View

Figure 6: Canonical Sleeve Antenna (CSA)

6(a) Isometric view, 6(b) Front view, 6(c) Sectional view

The CSA is fabricated as per design and photograph is shown in fig. 7.

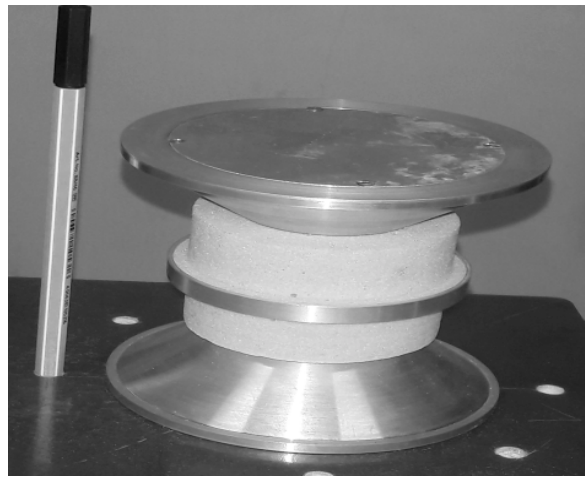

Figure 7: Photograph of Canonical Sleeve Antenna (CSA) 
The antenna is fabricated by machining blocks of Aluminium alloy. CSA is fed using 0.141" semi-rigid coaxial cable. An SMA receptacle is assembled to 0.141" coaxial cable and is fixed to the bottom plate of CSA. The centre conductor of the coaxial cable is soldered to the upper hemisphere and the outer conductor to the bottom hemisphere of CSA. Upper and lower parts of CSA are supported using Poly Urethane Foam dielectric support embedded within cylindrical sleeve.

\subsection{Measured results and discussion}

The VSWR measurement of the CSA antenna is carried out using a Vector Network Analyser. The radiation characteristics are evaluated in an anechoic chamber. The comparison of simulated and measured VSWR of the antenna is given in fig. 8 .

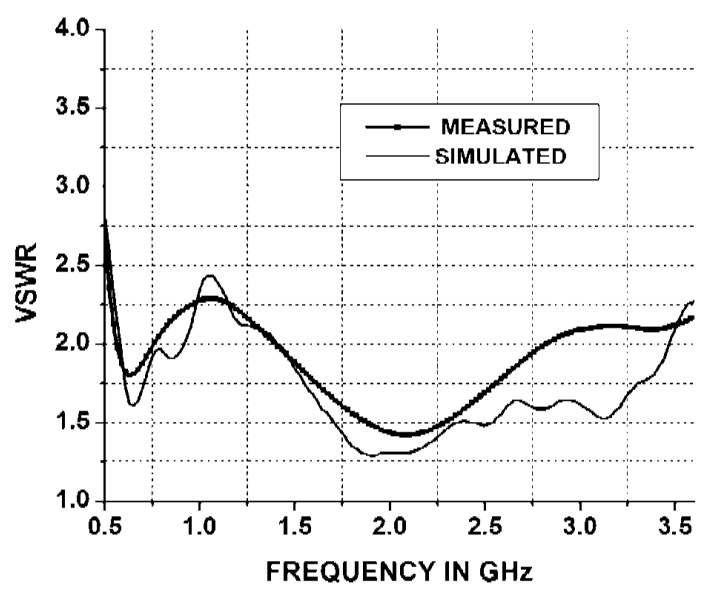

Figure 8: Simulated and measured VSWR of Canonical Sleeve Antenna (CSA)

The results indicate good agreement between the measured and simulated profiles of VSWR. Measured VSWR of less than 2.7:1 is achieved throughout the band $500-3600 \mathrm{MHz}$. The measured and simulated radiation patterns of the antenna are shown in fig. 9.

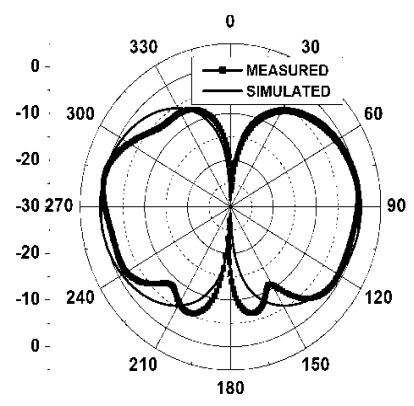

9(a) E-Plane Patterns

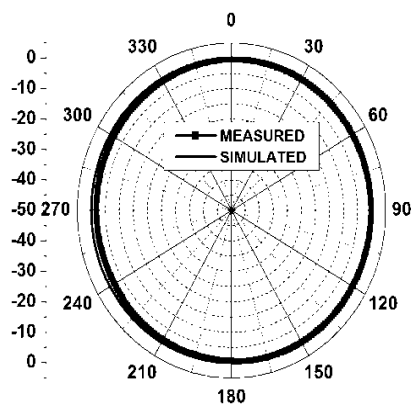

H-Plane Patterns

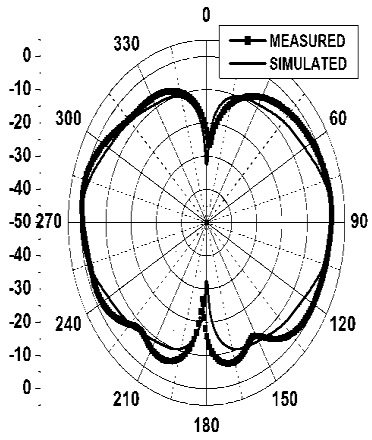

9(h) F.-Plane Patterns

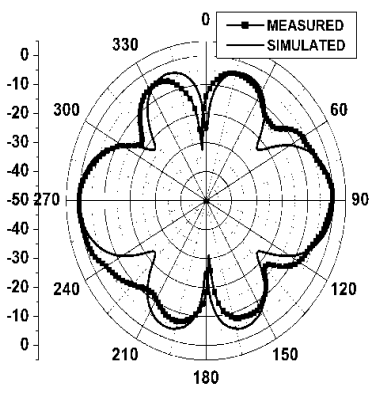

9(c) E-Plane Patterns

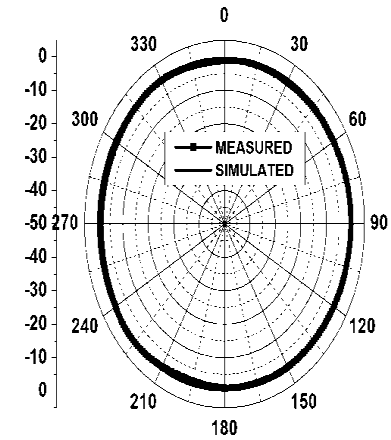

H-Plane Patterns

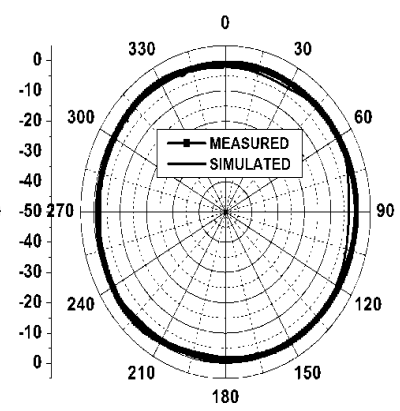

H-Plane Patterns
Figure 9: Simulated and measured radiation patterns of CSA

(a) E-Plane and H-Plane patterns at $0.5 \mathrm{GHz}$

(b) E-Plane and H-Plane patterns at $3 \mathrm{GHz}$

(c) E-Plane and H-Plane patterns at $3.6 \mathrm{GHz}$

CSA antenna exhibits good radiation patterns with figure of eight patterns in E-Plane and omnidirectional patterns in H-Plane. The $3 \mathrm{~dB}$ beamwidth of the E-Plane patterns of antenna varies from $35^{\circ}-66^{\circ}$. The maximum deviation from omnidirectionality in H-Plane patterns is within \pm $1.5 \mathrm{~dB}$. Comparison of the simulated and measured gain of CSA is shown in fig. 10. The measured Gain varies from 0 to $3.6 \mathrm{dBi}$.

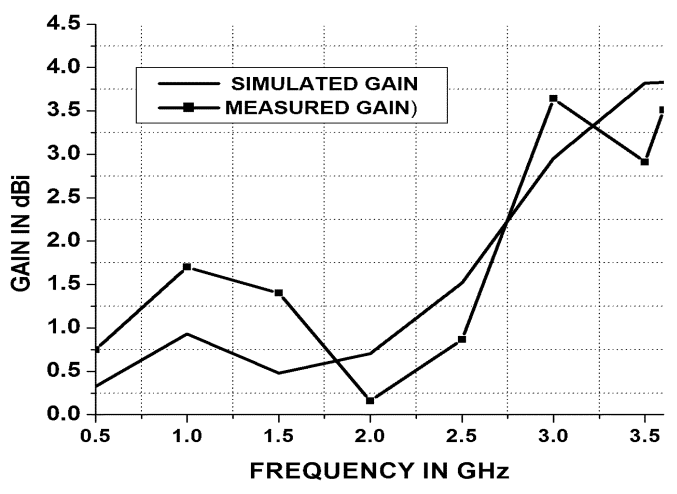

Figure 10: Comparison of measured and simulated Gain of CSA 
Table 1: Results of Simulation of Antenna Configurations studied in this paper

\begin{tabular}{|c|c|c|c|c|}
\hline Sl. No. & $\begin{array}{l}\text { Type of } \\
\text { Antenna }\end{array}$ & parameter values $(\mathrm{mm})$ & Size $\left(\mathrm{mm}^{2}\right)$ & Simulated Results \\
\hline 1 & $\overline{\mathrm{BCA}}$ & $\begin{array}{l}\mathrm{Hc}=49.84, \mathrm{Dc}= \\
148.28, \mathrm{~g}=0.92\end{array}$ & $99.69 \times 148.28$ & $\begin{array}{l}\text { VSWR } \leq 2.57: 1 \\
\text { Gain } \geq-1.15 \text { to } 3 \\
\text { dBi }\end{array}$ \\
\hline 2 & HDA & $\begin{array}{l}\text { Ds }=153.15 \\
\mathrm{~g}=4.43\end{array}$ & $157.59 \times 153.15$ & $\begin{array}{l}\text { VSWR } \leq 2.72: 1 \\
\text { Gain } \geq 0.1 \text { to } 1.4 \\
\text { dBi }\end{array}$ \\
\hline 3 & HDC & $\begin{array}{l}\mathrm{Hc}=44.64, \\
\mathrm{Dc}=109.64, \\
\mathrm{~g}=4.82 \\
\mathrm{Rs}=22.18\end{array}$ & $138.48 \times 109.64$ & $\begin{array}{l}\text { VSWR }<2.27: 1 \\
\text { Gain } \geq 0.95 \text { to } 3 \\
\text { dBi }\end{array}$ \\
\hline 4 & HDCCL & $\begin{array}{l}\mathrm{Hc}=25.62 \mathrm{Dc}= \\
115.34, \mathrm{~g}=3.82, \\
\mathrm{Rs}=24.68 \\
\text { Hcyl }=9.01\end{array}$ & $122.48 \times 115.34$ & $\begin{array}{l}\text { VSWR } \leq 2.45: 1 \\
\text { Gain } \geq 0.37 \text { to } \\
3.64 \mathrm{dBi}\end{array}$ \\
\hline 5 & $\begin{array}{l}\text { CSA } \\
\text { (Proposed } \\
\text { Antenna) }\end{array}$ & $\begin{array}{l}\mathrm{Hc}=26.7, \mathrm{Sl}=7.3, \\
\mathrm{Dc}=116.66, \mathrm{~g}=5.83, \\
\mathrm{Hcyl}=4.23, \mathrm{Ds}= \\
87.62, \mathrm{Rs}=21.85\end{array}$ & $111.43 \times 116.66$ & $\begin{array}{l}\text { VSWR } \leq 2.7: 1 \\
\text { Gain } \geq 0.25 \text { to } \\
4.4 \mathrm{dBi}\end{array}$ \\
\hline
\end{tabular}

Table 2: Comparison of Results of Canonical Sleeve Antenna (CSA) with Published Literature

\begin{tabular}{|c|c|c|c|c|}
\hline $\begin{array}{l}\text { Sl. } \\
\text { No. }\end{array}$ & Type of Antenna & $\begin{array}{l}\text { Frequency } \\
\text { Range and } \\
\% \text { Bandwidth }\end{array}$ & $\begin{array}{l}\text { Size } \\
\left(\mathrm{mm}^{2}\right)\end{array}$ & $\begin{array}{l}\text { Results (VSWR, Gain ) and } \\
\text { Remarks }\end{array}$ \\
\hline 1 & $\begin{array}{l}\text { Sleeve Helix } \\
\text { Antenna [3] }\end{array}$ & $\begin{array}{l}500-1750 \\
\mathrm{MHz} \\
111.11 \%\end{array}$ & $98 \times 60$ & $\begin{array}{l}\text { VSWR }<3.5: 1 \text {. Gain not } \\
\text { reported. Requires ground } \\
\text { plane of } 5500 \mathrm{~mm} \times 6700 \mathrm{~mm} .\end{array}$ \\
\hline 2 & $\begin{array}{l}\text { A Wideband Dual } \\
\text { Meander Sleeve } \\
\text { Antenna [4] }\end{array}$ & $\begin{array}{l}850-2050 \\
\mathrm{MHz} \\
82.75 \%\end{array}$ & $66 \times 32.8$ & $\begin{array}{l}\text { VSWR }<3: 1 \text {. Radiation } \\
\text { patterns and } \\
\text { Gain not reported. Requires } \\
\text { ground Plane of } 900 \mathrm{~mm} \mathrm{x} \\
900 \mathrm{~mm} .\end{array}$ \\
\hline 3 & $\begin{array}{l}\text { Low profile sleeve } \\
\text { monopole antenna } \\
{[15]}\end{array}$ & $\begin{array}{l}750-2660 \\
\mathrm{MHz} \\
112.02 \%\end{array}$ & $29 \times 132$ & $\begin{array}{l}\text { VSWR } \leq 2: 1 . \text { Gain not } \\
\text { reported. Requires a ground } \\
\text { plane of } 300 \mathrm{~mm} \text { diameter. }\end{array}$ \\
\hline 4 & $\begin{array}{l}\text { A novel multi- } \\
\text { sleeve antenna } \\
{[14]}\end{array}$ & $\begin{array}{l}0.8-2.5 \mathrm{GHz} \\
125.58 \%\end{array}$ & $104 \times 60$ & $\begin{array}{l}\text { VSWR } \leq 2: 1 \text {. Gain }: 1.4 \text { to } 2.2 \\
\text { dBi. Good Gain and radiation } \\
\text { Patterns. }\end{array}$ \\
\hline 5 & $\begin{array}{l}\text { CSA } \\
\text { (Proposed } \\
\text { Antenna) }\end{array}$ & $\begin{array}{l}500-3600 \\
\mathrm{MHz} \\
151.21 \%\end{array}$ & $111.43 \times 116.66$ & $\begin{array}{l}\text { VSWR } \leq 2.7: 1, \text { Gain : } 0 \text { to } \\
3.6 \mathrm{dBi} \text {. Requires no ground } \\
\text { plane, has good Gain and } \\
\text { radiation patterns. }\end{array}$ \\
\hline
\end{tabular}




\section{Conclusions}

A compact broadband Canonical Sleeve Antenna is designed and developed covering $500-3600 \mathrm{MHz}$. The antenna configuration consists of hemispherical dipole with conical extensions, cylindrical top loading and cylindrical sleeve for accomplishing broad bandwidth. The antenna has good gain compared to Biconical antenna and other antenna configurations studied. The antenna can be used as base station for trans-receive roles, access point antenna, repeater antenna in wireless communication systems. This antenna also finds use for ISM applications, spectrum monitoring, law enforcement applications and EMI / EMC test applications. Electronic Warfare (EW) requires broadband antennas. For all the above mentioned applications, Canonical Sleeve Antenna can be used in trans-receive roles.

\section{Acknowledgements}

The authors would like thank Dr A.K. Singh, OS \& Director, DLRL and Sri M.Balachary, OS \& Associate Director, DLRL for constant encouragement and support for carrying out the research work.

\section{References}

[1] Y.T. Lo, S.W. Lee, Antenna handbook, Vol.1, Van Nostrand Reinhold Pub. New York, pp. 3-27 to 3-30, 1994.

[2] Constantine A Balanis, Modern Antenna Handbook, John Wiley \& Sons, Inc., Publication, pp. 399-417, 2008.

[3] Shawn D. Rogers and Chalmers M. Butler, Wide-band Sleeve-Cage and Sleeve-Helical Antennas, IEEE Transactions on Antennas and Propagation, Vol. 50, No. 10, pp. 1409-1414, October 2002.

[4] M.Ali, S.S.Stuchly, K.Caputa, A Wideband Dual Meander Sleeve Antenna, Antennas and Propagation Society International Symposium, AP-S Digest, 18-23 June 1995.

[5] Bin Zhou, Qizhong Liu, YicaiJi, Research on A Novel Sleeve Antenna and its Applications, IEEE Intemational Symposium on Microwave, Antenna, Propagation and EMC Technologies for Wireless Communications Proceedings, pp. 330-333, 2005.

[6] James L. McDonal, FarzinLalezari and Dejan S. Filipovic, Design of a Broadband Biconically offset fed thick dipole, IEEE Antennas and Propagation Society International Symposium, 3-8 July 2005.

[7] Chritz Duncan and Edward Lule, Half Disc Element Dipole Antenna, IEEE Antennas and Propagation Society International Symposium, 3-8 July 2005.

[8] J. Anguera, J.P. Daniel, C. J. Mumbrú, C. Puente, T. Leduc, K. Sayegrih, and P. Van Roy, Metallized
Foams for Antenna Design: Application to FractalShaped Sierpinski-Carpet Monopole, Progress In Electromagnetics Research, PIER 104, 239-251, 2010.

[9] C.B.Ravipati and C.J.Reddy, Low profile Disc and Sleeve Monopole Antenna, IEEE Antennas and Propagation Society International Symposium, 3-8 July 1995.

[10] Chen Jin, Fu Guang, Wu Guang-de, A miniaturized Loaded Open Sleeve Antenna, IEEE International Symposium on Microwave, Antenna, Propagation, and EMC Technologies for Wireless Communications, pp. 523-526, 2007.

[11]Zhong-Da Wu, Fan-Yi Meng, Jun Hua, Mei-Liang Chen, Broadband Sleeve Monopole with very Small Ground Impedance Matching Network and Resistive Load, 5th Global Symposium on Millimeter Waves (GSMM 2012), May 27-30, 2012, pp. 88-91, 2012.

[12] Waqas Mazhar, Farooq Ahmad Tahirand Farooq Ahmad Bhatti, High-power broadband-loaded monopole antenna with sleeve ground plane for portable applications, Journal of Electromagnetic Waves and Applications, Vol. 28, No. 7, pp. 802-814, 2014.

[13] K. George Thomas, N. Lenin, and M. Sreenivasan, Wide-Band Dual Sleeve Antenna, IEEE Transactions on Antennas and Propagation, Vol. 54, No. 3, pp. 1034-1037, March 2006.

[14] T.Khumanthem, S.D.Ahirwar, C.Sairam, Ashwani Kumar, Design of Broadband Rectangular Sleeve Dipole Antenna Covering 850-2500MHz, International Conference on Recent Advances in Microwave Theory and Applications, 21-24, Jaipur, India, pp. 492-494, Nov., 2008.

[15] Tao Jian, Chang Su, Cheng-Yuan Liu, Ying-Song Li, A novel multi-sleeve antenna for mobile communications applications, 6th International Conference on Wireless Communications Networking and Mobile Computing (WiCOM), 23rd -25th Sep. 2010.

[16] S.L.Zuo, Y.Z.yin, Z.Y.Zhang and K.Song, Enhanced bandwidth of low profile sleeve monopole antenna for indoor base station application, Electronic Letters, Vol. 46, No. 24, 25 ${ }^{\text {th }}$ Nov. 2010.

[17] Z.-Y. Zhang, G. Fu S.Gong, S.Zuo and Q.Lu, Sleeve monopole antenna for DVB-H Applications, Electronics Letters, Vol. 46, No. 13, pp. 879-880, June 2010 